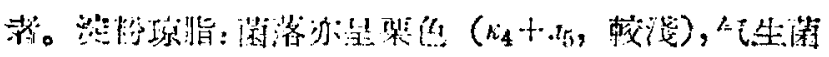

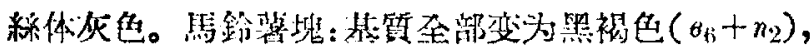

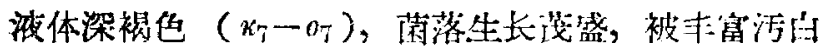

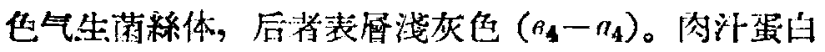

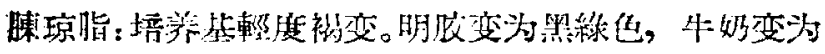

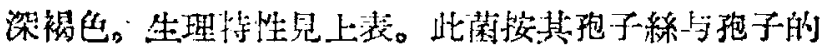
形状，与球抱放緎菌 (Act. globisporus Krassil-

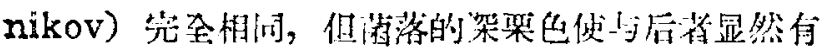

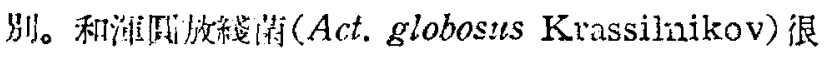

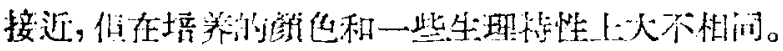
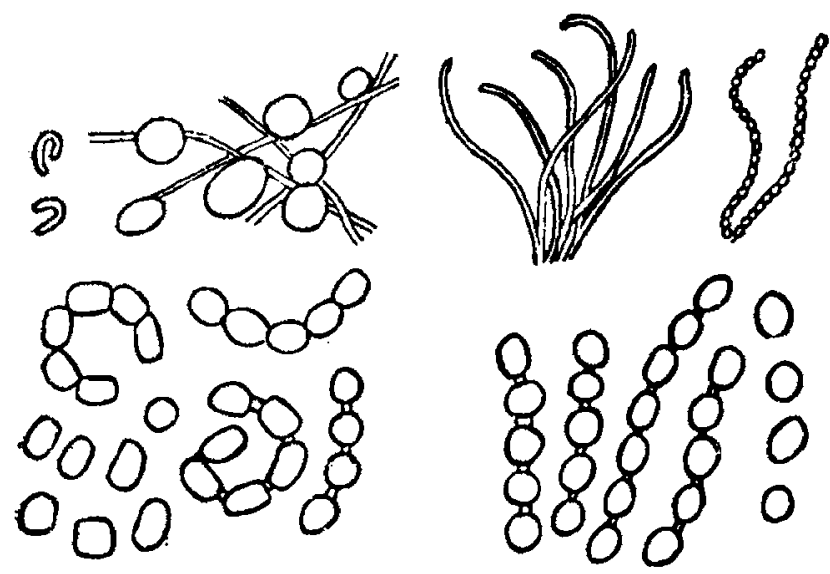

调 1 Act. agglomeralus

阔 2 At. caslanesslobisporus

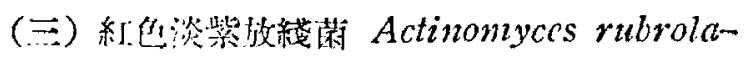
vendulae n. sp.

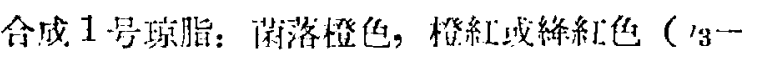

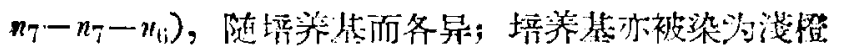

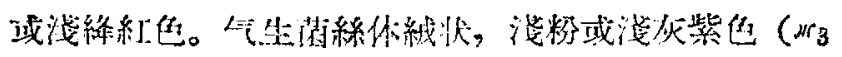
$+r_{5}$ 或 $\left.\mu_{2}+\gamma_{3}\right)$ ，随清抱了的成熟，灰任成分濑多。

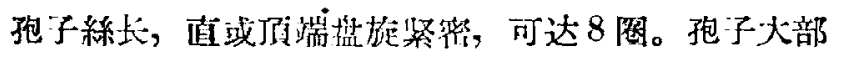

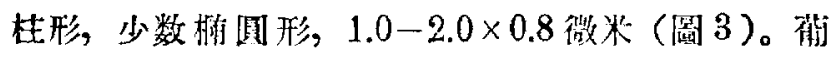

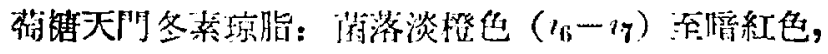

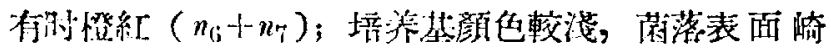

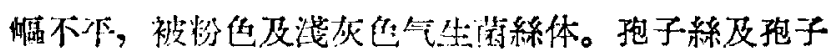

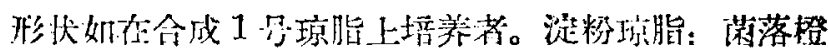

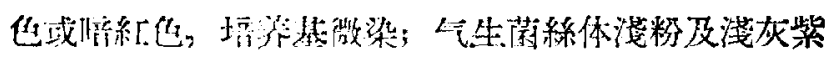

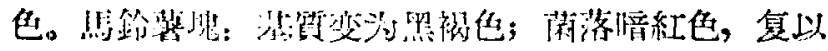

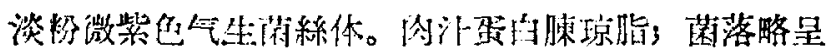

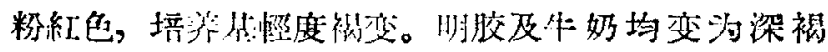

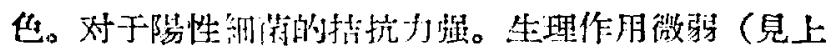

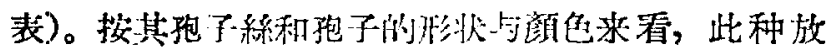

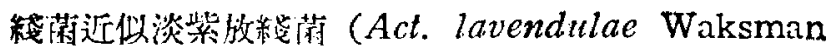

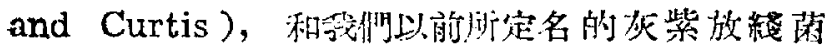
(Act. griseoloviolaceus) 也相近，但䒩落的頝色易 于将这三利得区叫开来。

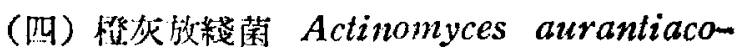
zriseus n. sp.

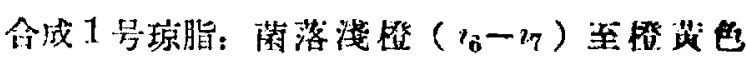
(13)，常呈大斑状，在老的培济內有时变为慆裀色。

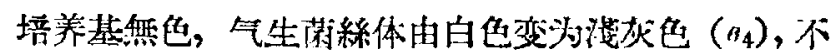

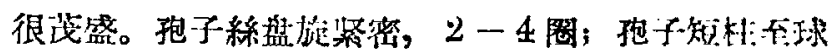

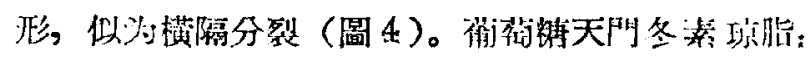

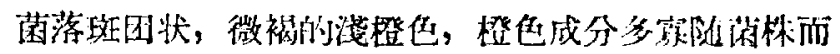

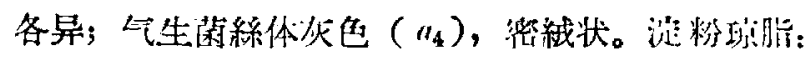

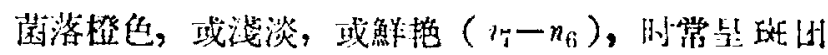

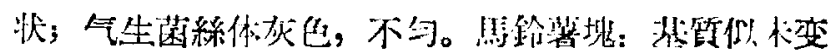

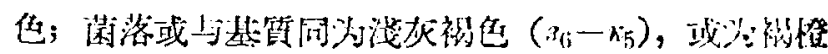

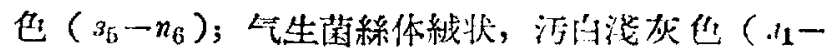

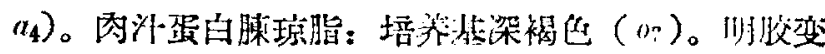

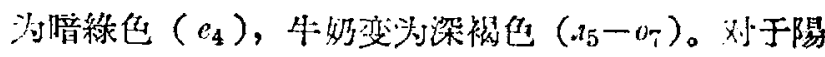

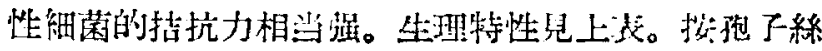


放䋊菌 (Act. griseus segmentosus) 相近。

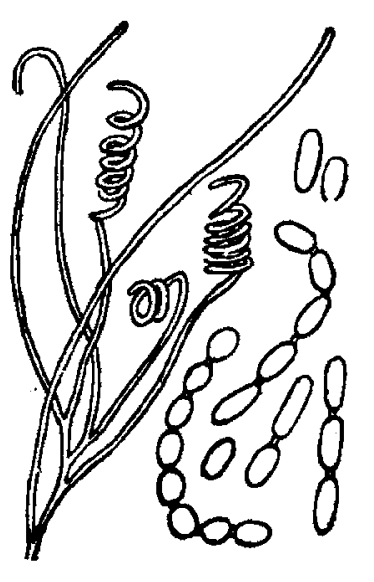

闻 3 Act. rubrola:endulae

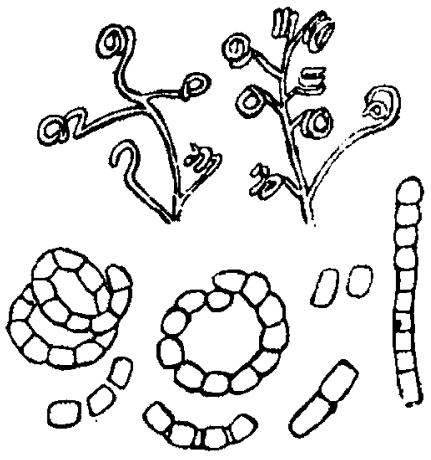

阔 4 Att. aurntiacogrisiss

閻 逊初

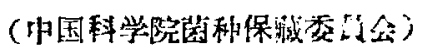
1957 年2月 21 日

\section{蛋白酶椊電深層培养条件 的試驗}

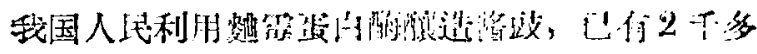

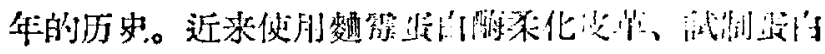

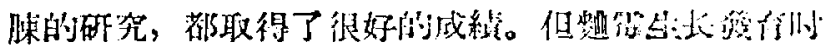

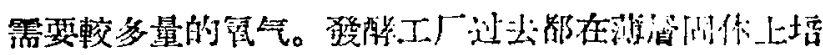

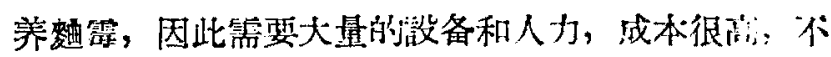

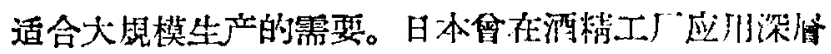

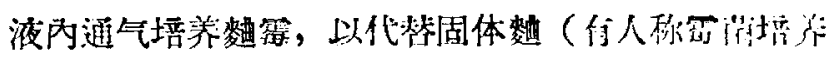

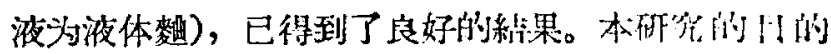
是为寻找液体䴮淛造的港本条件。

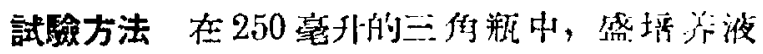

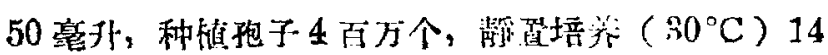




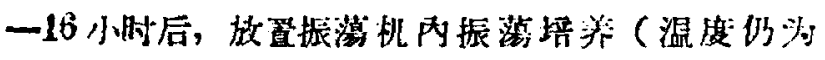

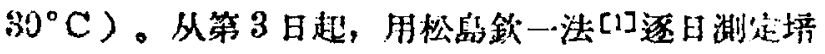

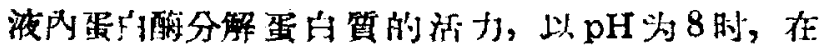

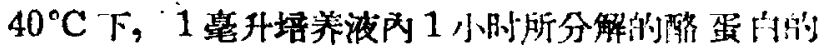
毫克数，作为蛋白酸活力的单位。



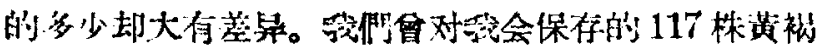

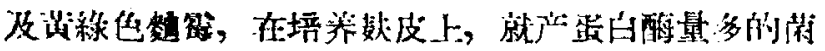

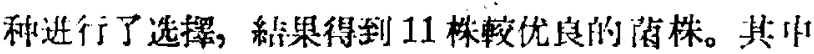

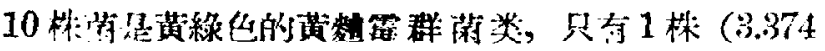

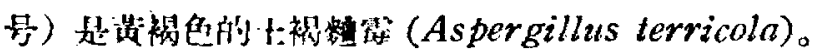

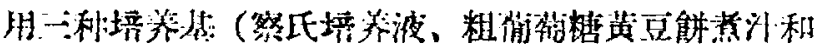

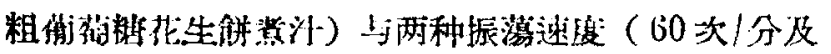

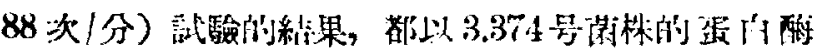

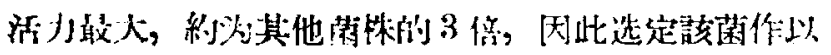



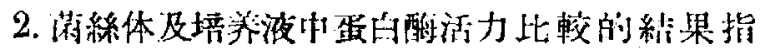

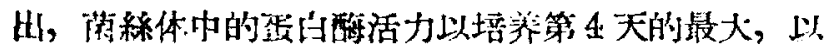

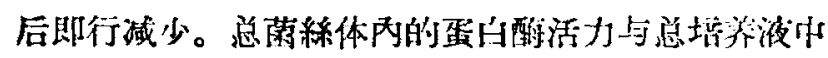

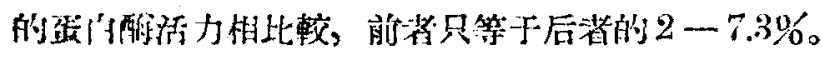

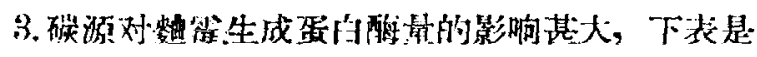

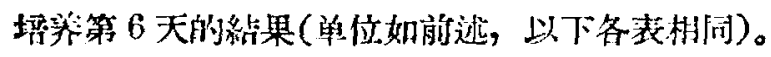

\begin{tabular}{|c|c|c|c|c|c|c|c|c|c|c|c|c|}
\hline 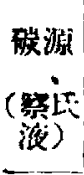 & 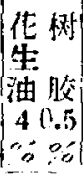 & $\begin{array}{l}\text { 俧考 } \\
\text { 生考 } \\
\text { 油 } \\
40.5\end{array}$ & $\begin{array}{l}\text { 化 } \\
\text { 注 }\end{array}$ & $\mid \begin{array}{c}\text { 油 } \\
\text { 酸 } \\
40 ; 0\end{array}$ & 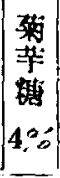 & $\left\{\begin{array}{l}\text { 吾 } \\
\text { 碳 } \\
4 \%\end{array}\right.$ & $\begin{array}{l}\text { H } \\
\text { 海 }\end{array}$ & $\begin{array}{l}\text { 许 } \\
\text { 踮 }\end{array}$ & $\left\{\begin{array}{l}\text { 树 } \\
\text { 胶 } \\
5 \% \text { 。 }\end{array}\right.$ & 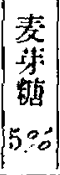 & 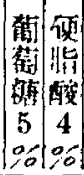 & $\left\{\begin{array}{l}\text { 治 } \\
4 \% \\
4 \%\end{array}\right.$ \\
\hline 蛋尚 & 400 & 400 & 333 & & 240 & 172 & 150 & 12 & 20 & & 25 & 100 \\
\hline
\end{tabular}

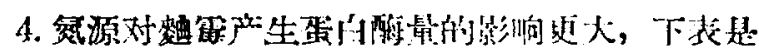



\begin{tabular}{|c|c|c|c|c|c|c|c|c|c|}
\hline 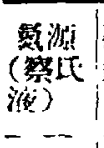 & 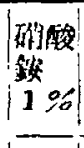 & 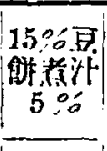 & 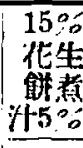 & $\begin{array}{l}\text { 碓酸 } \\
1.5 \circ 8\end{array}$ & $\begin{array}{l}\text { 蛋白 } \\
\text { 膊 } \\
2.0 \%\end{array}$ & $\begin{array}{l}\text { 烈 } \\
\text { 雪 } \\
2.0 \%\end{array}$ & 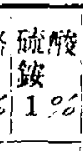 & & 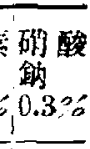 \\
\hline $\begin{array}{c}\text { 焣白醅 } \\
\text { 活力 }\end{array}$ & 400 & 333 & 250 & 72 & 20 & 15 & 0 & 0 & 400 \\
\hline
\end{tabular}

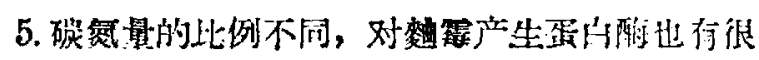
大的影响，下表所列的是第 6 天的結果。

\begin{tabular}{|c|c|c|c|c|c|c|c|c|c|c|c|}
\hline  & 15 & 20 & 25 & 30 & 40 & 40 & 40 & 40 & 40 & 40 & 40 \\
\hline 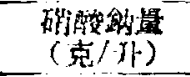 & 2.5 & 2. & 2.5 & $2.5 \mid$ & 2.5 & 1.5 & 2.0 & 2.5 & 3.0 & 3.5 & 4.0 \\
\hline 盆的䤃活力 & 300 & 400 & 400 & 400 & 400 & 1 & 240 & 400 & 400 & 250 & 250 \\
\hline
\end{tabular}

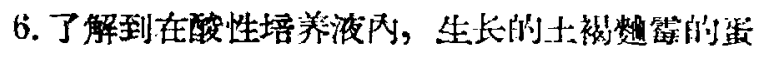
白褐的活力甚小，中性培济液较为合适。有些碳源琙视

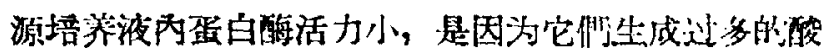


$5.08-5.13$ 时，蛋白酶的活力較小，的酸湲，氮化魰

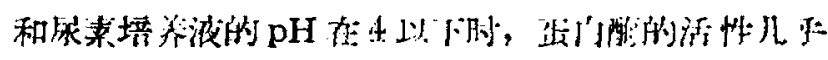

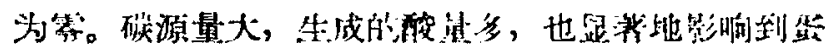
白酶活性的降低。

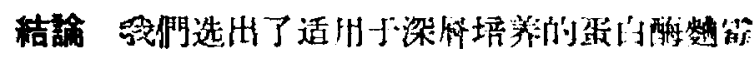

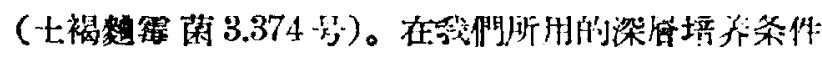

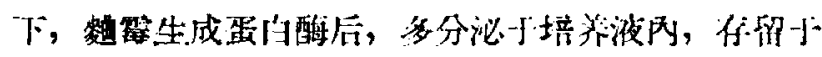

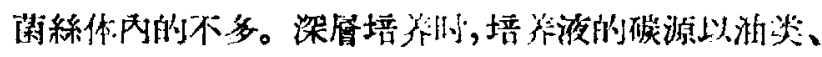

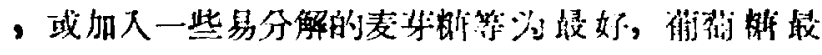

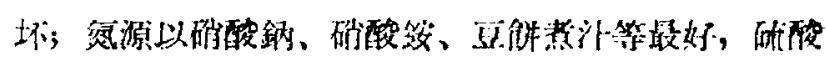

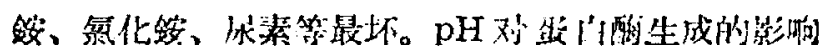

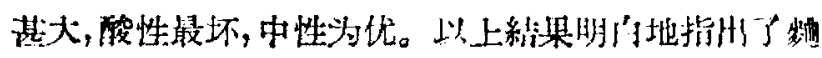

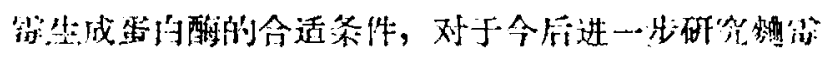

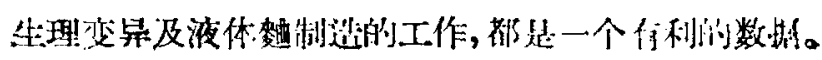

$$
\begin{aligned}
& \text { 㔨永闌 方心芳 严自正 }
\end{aligned}
$$



$$
\begin{aligned}
& 1957 \text { 年和组 }
\end{aligned}
$$

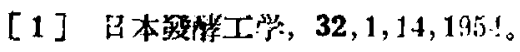

\section{徽生物利用 $\mathbf{N}$ - 磷酸苯丙 氨酸的試驗}

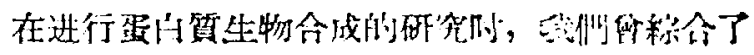

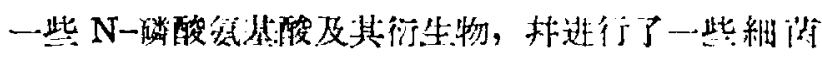

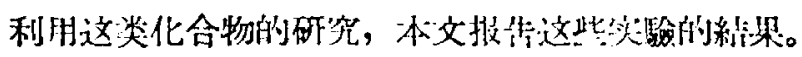

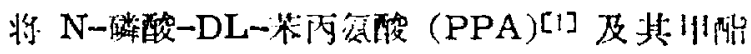

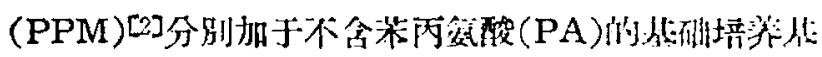

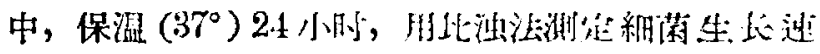
度, 綃果發現: Lactobacillus arabinosus 17-5 利

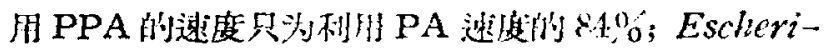

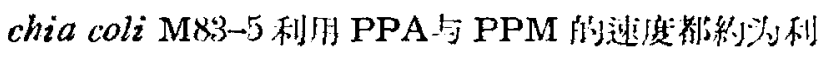
用PA的 60\%。这个秥果1;

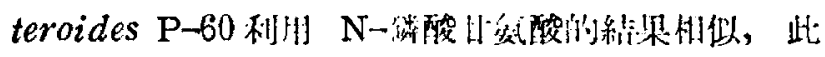

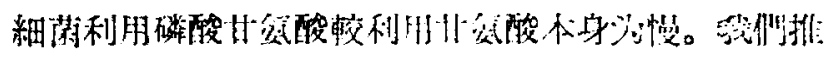

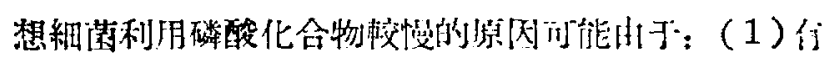
机磷化合物淩透細胞膜的能力較小[1]，风此进入彩胞 的速度也較慢; 或 (2) N-碳酸化合物必须尖經边磷

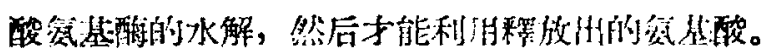

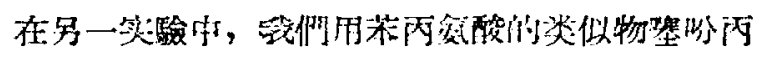

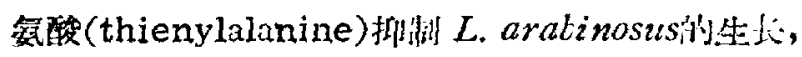

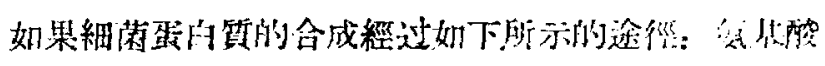

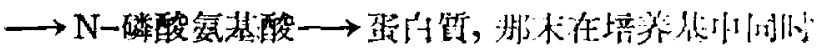

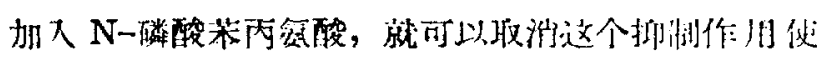

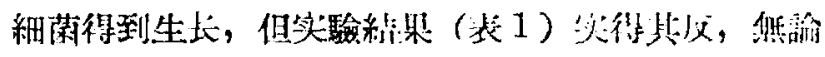



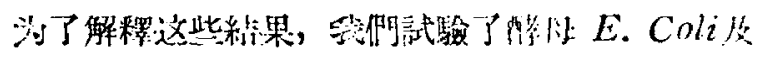

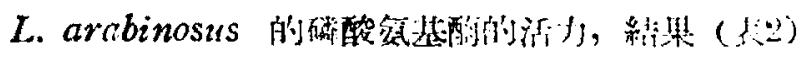

